\section{A school-wide assessment of social media usage by students in a US dental school}

\author{
M. R. Arnett, ${ }^{* 1}$ H. L. Christensen ${ }^{2}$ and B. A. Nelson ${ }^{2}$
}

IN BRIEF
- Betters the understanding of privacy
features on social media accounts.
Explains the difference between
the five most popular social media
applications.
- Provides examples of how to use five of
the most popular social media applications
in a course.

Social media sites have become an established means of communication due to the exponential growth in number of users across the world and the encouragement of interaction between users through site features. The purpose of this study was to determine the extent to which Loma Linda University School of Dentistry students use social media accounts, the types of accounts they prefer, their interest in incorporating social media into courses and their perceptions of the usefulness of social media in private practice. In addition, we wanted to determine the degree of student interest in the integration of these social tools into their instruction. One thousand one hundred and sixty-two students from Loma Linda University School of Dentistry were invited by e-mail to complete a confidential 18 item multiple choice survey through Surveymonkey.com. The overall response rate was 30\% $(n=351)$ from the pooled response periods; the first in 2011 and the second in 2013. Similar to other studies, Facebook was used by $91 \%$ of the School of Dentistry students, and less than half used Google+, Twitter and Linkedln. Of the respondents, 68\% of students reported communicating on social media daily and $80 \%$ saw value for practising dentists to operate accounts. Time and privacy concerns were the largest barriers to usage at $16 \%$ and $12 \%$ respectively. One third of respondents were in favour of the incorporation of social media in their courses.

\section{INTRODUCTION}

Every day, thousands of new accounts are created on Facebook, Twitter, Google+ (G+), LinkedIn and other social media networking sites, and millions more use social media with regularity. More than $80 \%$ of US adults reportedly use social media accounts monthly ${ }^{1}$ and previous studies have shown approximately 90\% of college students use Facebook accounts. ${ }^{2-5}$ Mashable, a media news blog, reported that Americans spend approximately 8 hours a month on Facebook. ${ }^{5}$ With over 900 million users, most of whom log in at least monthly, ${ }^{4}$ Facebook has experienced exponential growth for a 10-year-old company. As with social media applications and uses, the number of users increases daily. In 2011, social media usage became the number one activity on the web. ${ }^{6}$

Social media sites are engaging by nature and widely adopted by students. Brandtzaeg et al. ${ }^{3}$ queried 1,200 participants

\footnotetext{
${ }^{1}$ Assistant Professor, ${ }^{2}$ Associate Professor, Loma Linda University School of Dentistry, 11092 Anderson St, Loma Linda, CA 92350, United States

*Correspondence to: Margie R. Arnett

Email: MArnett@llu.edu
}

\section{Refereed Paper}

Accepted 4 July 2014

DOI: 10.1038/sj.bdj.2014.956

${ }^{\circledR}$ British Dental Journal 2014; 217: 531-535 about why they participated in social networking sites. The results indicated that $31 \%$ of users desired to contact new people with shared interests, 21\% wanted to keep in touch with friends and 14\% were interested in general socialising. Social media tools can be used by faculty and institutions as an educational resource that compliments educational processes for better comprehension of the material. ${ }^{7}$ Chickering and Gamson suggest that students must do more than just listen to a lecture. ${ }^{8}$ Students must read, write, discuss or be engaged in solving problems to digest and understand the material. ${ }^{8-10}$

Most colleges and universities utilise social media sites to increase communication with students, alumni, faculty, staff, fans, administration and potential students through a variety of activities. These activities include highlights of admission activities, a showcase for faculty and student research, announcements regarding athletic events, continuing education courses and other special events, as well as links to the university website, online magazine, other social media sites and RSS feeds.

While sites such as Facebook, G+ and Twitter are commonly used for socialising and networking, university faculty have also begun using these accounts in their courses. ${ }^{7,10-17}$ Pascarella et al. ${ }^{18}$ state that some of the most effective faculty members use social media to create a more collegial relationship with their students. Social media can be used as a platform for active learning in dentistry by providing faculty with a simple and effective way to engage students online in real time, with minimal hindrances. However, professional boundaries, ethics and legal concerns surrounding complex issues can arise with the use of social media in a medical academic environment. ${ }^{18-20}$ Recent literature about established social media policies in the health professions and the appropriate use of social media in these settings yielded few results. ${ }^{21,22}$

This article will present the results of a survey of Loma Linda University School of Dentistry (LLUSD) students, a discussion of the implications of the study findings, a brief description of several common social media networks and tips to incorporate these networks into a course. Loma Linda University School of Dentistry opened in 1953, and is a Seventh-day Adventist institution, located in Southern California. The average student was aged 24.8 years upon admission, therefore fitting the description of a millennial. Millennials are defined as the generation born from the early 1980 s to 2000 .

\section{Social media applications}

All social media sites discussed in this article are available free of charge to users. Facebook 
is the most popular social media network. Studies have shown that $90 \%$ of college students use Facebook accounts. ${ }^{2-5}$ Twitter is considered a micro-blog, and users must be succinct with their 140 character posts. It is best described as social messaging and is similar to public texts. Twitter is gaining in popularity among faculty and administrators as a communication tool that does not involve playing games, 'poking' friends or 'tagging' photos. ${ }^{13}$ Faculty Focus conducted a survey of approximately 2,000 higher education professionals that showed that $71.8 \%$ of those who use Twitter expect their usage to increase this year. ${ }^{23}$ Additional findings predicted relatively strong adoption rates of Twitter among higher education professionals. ${ }^{24}$ Google+ $\left(\mathrm{G}+\right.$ ) was launched in 2011..$^{25}$ In 2013, G+ had fewer active users than Facebook or Twitter, but is quickly gaining in popularity. G+ has several distinctive benefits, including video chat called 'Hangouts', Google searches, Gmail access from within $\mathrm{G}+$ and document sharing. Overall, G+ settings, including privacy settings, are more intuitive and, in general, easier to use than those of Facebook. LinkedIn is a businessoriented social media site for professional networking, job searches and recruiting. Users post a personal profile, job history, projects, published works, accomplishments, skills, expertise and community activities. ${ }^{26}$ Pinterest is a newer social networking site that is focused on a user's visual interests. In March 2012, Pinterest surpassed LinkedIn for number of users and became the third largest social networking site. ${ }^{27}$ Pinterest allows users to 'pin' and describe photos to virtual bulletin boards, each of which can be categorised by a theme. Any type of visual media (images, videos and infographics) can be posted, categorised and shared on Pinterest, and then shared directly to other social networking sites.

\section{METHODS}

The survey used in this investigation was adapted with permission from the instrument used by Dr Shawneen Gonzalez in her dental radiology course at the University of Nebraska Medical Centre College of Dentistry. The 18 multiple-choice questions used in this study included the option to write in a response. Institutional Review Board approval was obtained in December 2011 to survey all 599 students who were currently attending LLUSD and again for the 563 students attending in December 2013 (Fig. 1). The confidential and voluntary survey was accessed through SurveyMonkey, a web-based survey and evaluation system, with a link to the survey provided in the e-mail invitation. Four reminder requests

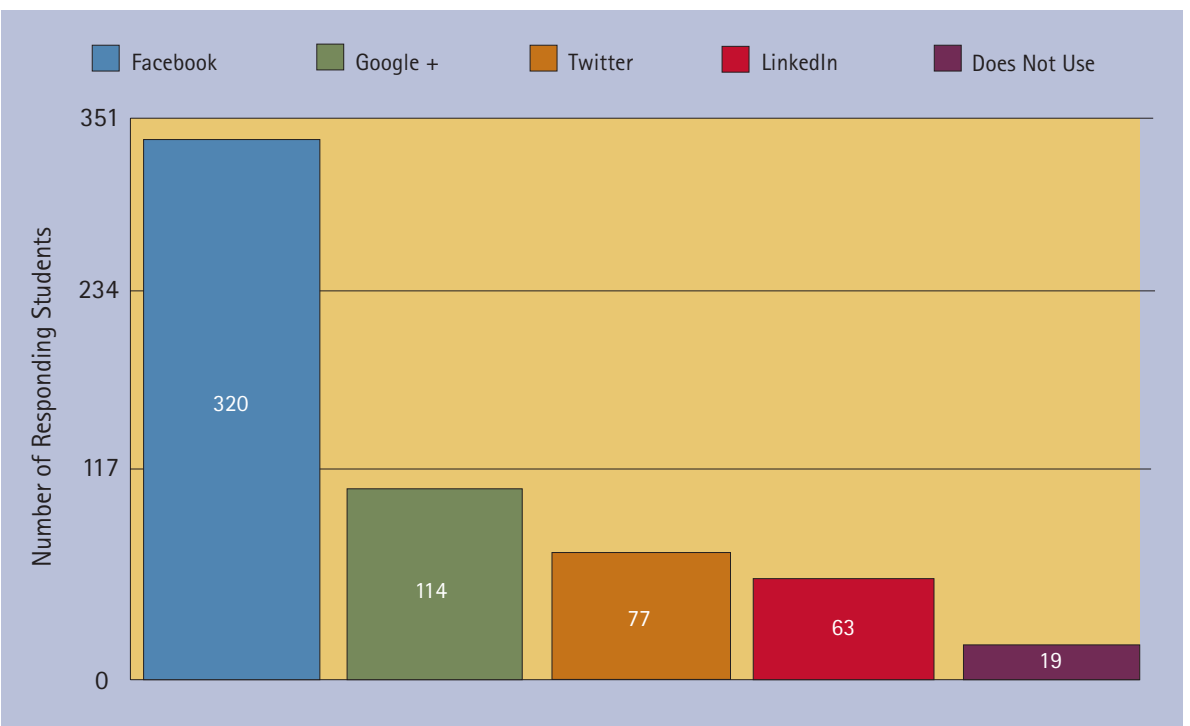

Fig. 1 Types of social media accounts used by students

Table 1 Types of students responding to survey $(n=351)$

\begin{tabular}{|l|l|}
\hline Class & Percent of class, (n) \\
\hline D1 & $37.6 \%(72)$ \\
\hline D2 & $35 \%(68)$ \\
\hline D3 & $24.4 \%(48)$ \\
\hline D4 & $23.4 \%(46)$ \\
\hline Dental hygiene & $39.3 \%(68)$ \\
\hline International dentistry program & $34.4 \%(31)$ \\
\hline Advanced education residents & $17.4 \%(32)$ \\
\hline Total respondents & $30 \%(351)$ \\
\hline Percent of total: dental (d1-d4, idp) & $75.7 . \%(265)$ \\
\hline Percent of total: dental hygiene & $18 \%(68)$ \\
\hline Percent of total: advanced education residents & $9.1 \%(32)$ \\
\hline
\end{tabular}

were e-mailed to students and residents during a single 30-day period in 2011 and again in 2013. Verbal announcements were made to each class, reminding them about the online voluntary school-wide survey: two announcements were made in 2011 and two announcements in 2013. Students were allowed to submit a hard copy of their responses. Because this survey was offered to all enrolled students at LLUSD, in 2011, and again in 2013, some students completed the survey twice. The survey was intended as a snapshot of student perceptions, and to evaluate if student perceptions changed from 2011 to 2013. The survey was anonymous, so investigators had no way of matching the students from each year.

In the survey, students were asked to identify all social media sites where they were registered, as well as their use of these sites. The students were also asked about their interest in the LLUSD social media sites, which include Facebook, Twitter and Foursquare. Students who indicated that they did not use social media sites were asked to identify barriers to using such networks. Students were also asked about their interest in having faculty incorporate social media into course instruction. Survey data was collected and analysed using frequency counts and descriptive statistics.

\section{RESULTS}

The data from both surveys was pooled, resulting in an overall response rate of 30\% $(\mathrm{n}=351)$. The majority of the survey respondents were dental students (67\%), 18\% were dental hygiene students, 9\% were advanced dental education students or residents and 9\% were from the International Dental Program (Table 1). More than half of the students (67.7\%) use social media daily, $40 \%$ use it multiple times a day and 5.2\% of the students keep a social account open all day. 


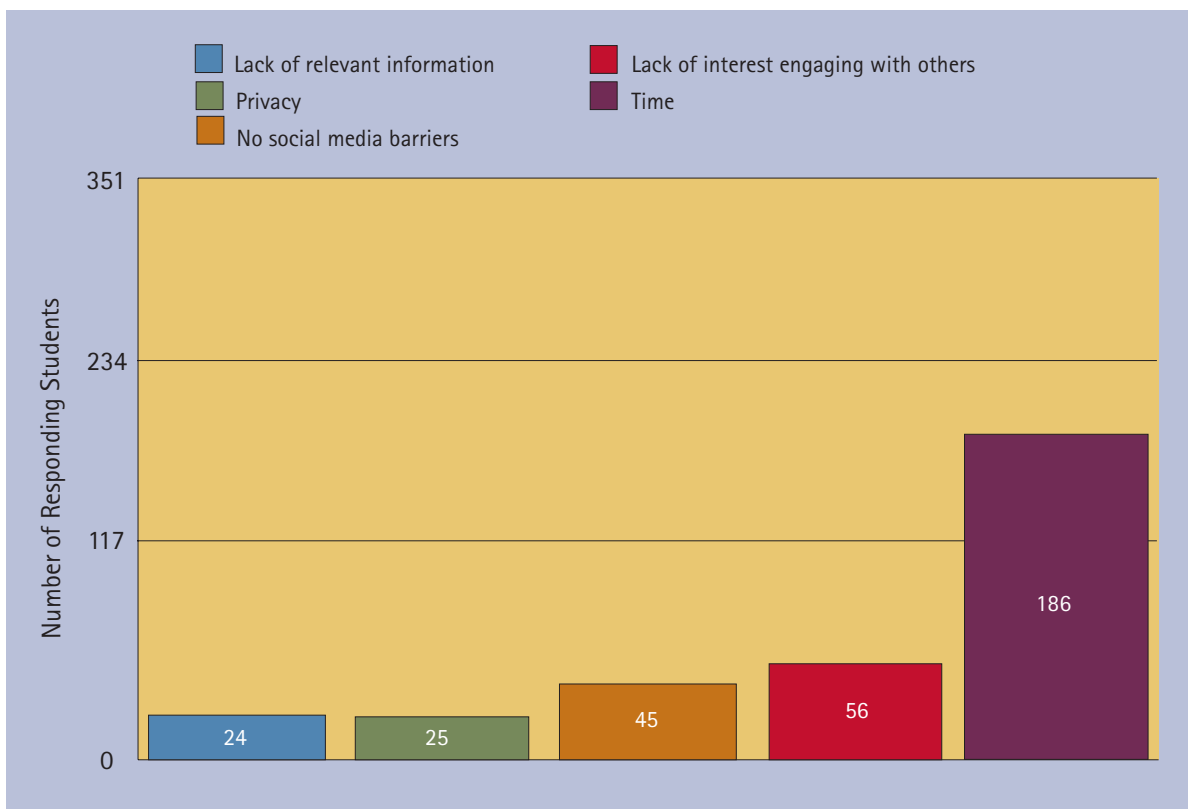

Fig. 2 Reasons for not participating in social media

Similar to other studies, ${ }^{2-5}$ Facebook was the most popular social network used by $91 \%$ of the School of Dentistry students, 32.5\% had a Google+ account, 22\% were registered with Twitter, 17.5\% with LinkedIn, 2\% used Foursquare and 3.5\% reported using no social media networks at all (Fig. 1). A very small number of respondents were registered for social media accounts that they did not use. There are a number of students who are not on Facebook, but do use LinkedIn and Google+.

Of the 351 respondents, 16\% indicated time was a significant factor inhibiting their use of social media, $12.8 \%$ had privacy concerns, 7.1\% lacked interest engaging with others online and 6.8\% believed social media lacks relevant information (Fig. 2). Of the $16 \%$ of respondents who do not or who rarely participate in social media, 50\% stated their lack of social media use was due to time factors, 60\% were concerned with privacy, $69 \%$ had a lack of interest engaging online and $31.1 \%$ felt there was a lack of relevant information. Comparing the 2011 and 2013 responses, the barriers of time, lack of relevant information, and privacy concerns all increased by $2 \%$.

Comparing LLUSD student responses from 2011 and 2013, the percentage of students registered on LinkedIn increased by 5\% while the registrants on Facebook and Google+ each increased by $3 \%$. These increased percentages are similar to those of the recent 2013 Pew Report Social Media Update, which also reported a growth in social media use by adults and stated $42 \%$ of adults now use multiple social networking sites; Facebook, however, is still the preferred platform. ${ }^{28}$ The percentage of students who are not registered with social media accounts remained essentially unchanged at 5.2\% (2011) and 5.3\% (2013).

When asked if they would be interested in having social media incorporated into their educational experience, $65.4 \%$ of students reported no interest in the idea. It was anticipated that there would be a strong correlation between students who use social media with more frequency and regularity, and those students that wanted social media incorporated into their instruction. However, at every level of social media usage (all day, multiple times a day, daily, weekly, monthly), the proportion of respondents who were in favour of the incorporation of social media in their courses was the same (one third).

In 2013, the majority of students (80\%) saw value for dentists to have social media accounts for their practice. The percentage of positive respondents to this item increased by 8\% from when it was first asked in 2011.

\section{DISCUSSION}

Over 1,000 health profession students were assessed in 2010; these students stated that online media is their primary source of information and Facebook was used most often. A growing number of medical practitioners and students are using social media sites, ${ }^{29,30}$ as a forum to discuss case studies, ${ }^{22}$ educate students, ${ }^{31}$ and communicate with colleagues, ${ }^{32}$ and patients. ${ }^{30,33}$ There is evidence in the literature that suggests Facebook may be effective in enhancing student learning and collaboration in health professions education. ${ }^{13,16,34}$

\section{Privacy concerns}

Although the use of social media in education does have promise, one of the major concerns for faculty ${ }^{34}$ and the students who answered this survey is the possible blurring of the line between the personal and professional lives, particularly with Facebook. Attendees at the 2012 American Dental Education Association annual session workshop, 'Using social media in dental education', expressed concern about having current students as 'friends' on Facebook. Many faculty members do not consider students as friends, and accepting a Facebook 'friend request' from a student can blur these boundaries. Faculty and students might have a misunderstanding of how a Facebook page operates and believe that faculty would have to be a Facebook 'friend' for an educational process to work, and thus have access to their private information.

Privacy settings in Facebook can be adjusted to limit information. In the case of a course, the faculty member can create a group page for students. When a private group is created on Facebook, users of the group do not automatically have access to the creator's personal account information. Students can adjust privacy settings to limit the amount of personal information accessed by their classmates and professors. It is possible to block all information other than name from a search on Facebook, while maintaining a presence in a Facebook group.

There were a number of LLUSD students who are not on Facebook, but who do use LinkedIn and Google+. It is possible that those students see a distinction between professional and personal use of social media or have concerns with the Facebook privacy settings.

\section{Using Facebook to supplement a course}

There are many benefits of using a Facebook group. From the group page, a professor can make announcements about class cancellations, room or time changes. The majority of LLUSD students (91\%) use social media to some extent and 67.7\% communicate daily on social media. Course-related information posted through sites such as Facebook might have a better chance of being read in a timely manner than those posted through other methods, such as a university e-mail. The classroom experience can be enhanced by posting course-related articles, questions or quizzes as a form of test preparation, or questions to accompany images that show restoration margins, crown preparations, dentures or radiographs. Additionally, online discussions can be assigned and related to anything posted on the group page. Professors can hold virtual office hours and provide mentoring from off-campus locations. A specified period of time could be set aside for office hours and students can log in 
to have questions answered in an individualised manner. It is noteworthy that Facebook has an algorithm that prevents all fans from seeing posts in their personal timeline. This algorithm is weighted and based on the amount of interaction a fan has with the page through sharing, commenting and liking posts. The majority of fans must navigate to a brand's Facebook page to engage with the contents.

\section{Applying G+ in higher education}

Second in popularity was Google +, with $32.5 \%$ registered students, although only $4.2 \%$ of the students used G+ as their primary social media network. The first survey was given 2 months after the launch of $\mathrm{G}+$, which accounts for the number of students (33.7\%) that had a G+ account in 2013 as compared with those (29.8\%) with accounts in 2012. G+ has a feature known as 'Hangouts', which is a streamlined and simple open video chat. Faculty can leave their browser open and literally hang out until students join the Hangout. Similar to online office hours using Facebook or Twitter, in Google+ this can include a video session for a tutorial. The 'Hangout' feature provides for multi-user video chat and groups of students can gather to work through particularly difficult problems or get advice on the progress of a project. It allows faculty the ability to video chat with students, without leaving home or the office. G+ also has the ability to organise people by groups; in $\mathrm{G}+$ the groups are called 'circles'. For example, a class can be one circle of students. Adjusting the preferences to specific circles allows one to share individualised content. While in a 'Hangout', one can share YouTube videos to explain a concept. The Google search bar remains operational while on $\mathrm{G}+$; students can find the latest research on a topic or procedure without exiting the application. Additionally, G+ has significantly fewer ads and reaches all followers who are online at the time. G+ also e-mails users content that may have been missed while away from the application.

\section{Twitter and classroom participation}

Twitter may be favoured over the other social media applications because of the minimal amount of personal information requested and its succinct messages. Unlike Facebook, Twitter privacy settings have been straightforward and have changed little since Twitter's introduction. Twitter does not describe people as friends, but as followers. Like G+, Twitter has significantly fewer ads and reaches all followers who are online at the time. Twitter is best described as public texting, so real-time $\mathrm{Q}$ and $\mathrm{A}$ using Twitter works well in the classroom. During instruction, students can tweet questions to the professor, who in turn can read and answer these questions out loud. This type of semi-anonymous interaction can be beneficial for shy students and others who are unwilling to risk speaking up in a competitive environment such as dental school. In addition, Tweets can be categorised with the use of a hashtag (\#) for ease of reference.

\section{Collaborating with Linkedln}

LinkedIn brings together professionals with common interests to form new collaborations, projects or research; thus it is profession rather than pop-culture driven. Groups and forums are related by topic, which are moderated by an administrator. In addition to personal profiles, business profiles are posted and often include a company profile, products page and employment opportunities. Evidence was not found of LinkedIn being used to supplement a dental course, but use of this social media site might assist students as they map their career path after they graduate. Connections can be used to collaborate on a project, find a job, or learn about a potential employer.

\section{Pinterest is for visual learners}

Pinterest is focused on a user's visual interests and can be used as a presentation tool in class with each image linked to an explanation, or question. Boards can be categorised to group similar subjects together; such as clinical pinboards for radiographic anatomy, oral radiology, tooth anomalies, periodontal diseases or oral pathology. Links to images or Pinterest boards can be posted on other social media applications.

\section{LIMITATIONS}

There may have been an unintended limitation to the study. The lead author worked in the School of Dentistry Dean's office and all e-mails were sent from her e-mail address, which includes a signature indicating the office in which she works. Students may not have answered or answered honestly regarding the regularity students post to social media networks, possibly fearing administration would think poorly upon their time management skills in relation to their scholastic efforts. This is theorised from comments such as, 'Administration shouldn't get involved in social media. It will ruin everything!' and inconsistent findings in two questions. First, 53\% of the respondents stated they only post to Facebook one to five times a week and only $6 \%$ tweeted. But later, when questioned on the regularity of social media usage, $41.1 \%$ stated they use it multiple times a day and 5.4\% stated they have it open all-day long.

\section{CONCLUSIONS}

The majority of LLUSD students (91\%) used Facebook as their primary account, with $65.1 \%$ posting messages daily. Time and privacy were noted as concerns about using social media, and only 35\% of the respondents saw value for social media to be incorporated into their instruction.

The majority of student respondents (83\%) saw value for practising dentists to have a professional presence on social media, which is not surprising. Millennials are the largest demographic who support and engage with brands on social media. They support brands by 'liking' on Facebook, clicking ' +1 ' on G+, 'retweeting' on Twitter and 'repinning' images on Pinterest. Additionally, they may also recognise that social media can reduce a business's overall marketing costs. Social media can enhance customer service by virtue of its easy availability to patients for comments, questions or concerns.

These results from LLUSD students about the role of social media in dental education differ from findings reported in previous university studies; these studies reported that many millennials prefer a digital approach to learning and appreciate online learning opportunities. This study did not ask why students did not have interest in having social media incorporated into their instruction. The $65 \%$ of respondents who lacked interest in this incorporation, may feel that dental school is very challenging and social media is a distraction to their studies. They may also prefer a separation between personal and social life and school assignments. However, attitudes about technology change over time and social networking is rapidly growing and constantly evolving. Potential benefits of technology such as increased student interaction should be balanced with the potential disadvantages. Thus, there is room to increase the professional use of social media networks in dental education and the technology can serve pedagogy when facilitated by an inspired teacher. Before incorporation of social media in a course, training for faculty is crucial and should be focused on the most popular social networking sites. A larger scale survey is needed to determine demographic trends.

1. Corcoran S. The broad reach of social technologies - a social computing report. Forrester; Online report available at http://www.forrester.com/The+Broa $\mathrm{d}+$ Reach+Of+Social+Technologies/fulltext/-/ERES55132?docid=55132. (accessed August 2014).

2. 7 things you should know about Facebook. Educause, 2006. Online article available at http://net. educause.edu/ir/library/pdf/ELI7017.pdf (accessed August 2014).

3. Brandtzaeg P B, Hein J. Why people use social networking sites. Proceedings of the $\mathrm{HCl}$ International 2009. San Diego, CA, USA, 19-24 July. In Ozok A A, Zaphiris P (eds) Online communities, LNCS. pp 143-152. Berlin: 
Springer-Verlag, 2009.

4. Hepburn A. Facebook statistics, stats \&t facts for 2011. Digital Buzz, 2011. Online article available at http://www.digitalbuzzblog.com/facebook-statisticsstats-facts-2011/ (accessed August 2014)

5. Parr B. You spend 8 hours per month on Facebook Mashable, 2011 Online article available at http:/ mashable.com/2011/09/30/wasting-time-onfacebook/ (accessed August 2014).

6. Qualman E. 10 wow social media statistics. Socialnomics, 2011. Online article available at http:// www.socialnomics.net/2011/06/07/10-wow-socialmedia-statistics/ (accessed August 2014).

7. Estus E L. Using Facebook within a geriatric pharmacotherapy course. Am J Pharm Educ 2010; 74: 145 .

8. Chickering A W, Gamson Z F. Seven principles for good practice in undergraduate education. AAHE Bulletin 1987; 39: 3-7.

9. Chickering A W, Gamson Z F. Applying the seven principles for good practice in undergraduate education. San Francisco, CA: Jossey-Bass, 1991.

10. Chickering A W, Gamson Z F. Development and adaptations of the seven principles for good practice in undergraduate education. New Directions for Teaching and Learning 1999; 80: 75-81.

11. George D R, Dellasega C. Use of social media in graduate-level medical humanities education: two pilot students from Penn State College of Medicine. Med Teach 2011; 33: 429-434.

12. Grey K, Annabell L, Kennedy G. Medical students' use of Facebook to support learning: insights from four case studies. Med Teach 2010; 32: 971-976.

13. Miner Z. Twitter goes to college. US News and World report, 2010. Online article available at http:// www.usnews.com/education/articles/2010/08/16/ twitter-goes-to-college- (accessed August 2014).

14. Rice A. Students push their Facebook use further into course work. The Chronicle of Higher Education, 2011. Online article available at http://chronicle.com/blogs/ wiredcampus/students-push-their-facebook-usefurther-into-academics/33947 (accessed August 2014).

15. Roblyer M D, McDaniel M, Webb M, Herman J, Witty $J$ V. Findings on Facebook in higher education: a comoparison of college faculty and student uses and perceptions of social networking sites. Internet and Higher Education 2010; 13: 134-140.

16. Skiba D J. Nursing education 2.0: social networking for professionals. Nurs Educ Perspect 2008; 29: 370-371.

17. Trueman M S, Miles D G. Twitter in the classroom: twenty-first century flash cards. Nurse Educ 2011; 36: 183-186.

18. Pascarella E T, Terenzini P T. How college affects students: a third decade of research. San Francisco, CA: Jossey-Bass, 2005.

19. Social media use: practical and ethical guidance for doctors and medical students. British Medical Association, 2011. Available from: http://www. bma.org.uk/practical-support-at-work/ethics/ ethics-a-to-z (accessed August 2014)

20. McMahon J W. Professionalism in the use of social media. American Medical Association, 2010.

21. Cain J, Fink J L. Legal and ethical issues regarding social media and pharmacy education. Am J Pharm Educ 2011; 74: 184.

22. Kind T, Genrich G, Sodhi A, Chretien K C. Social media policies at US medical schools. Med Educ Online 2010; 15: 1-8.

23. Bart M. Social media usage trends in higher education faculty. Special report. Magna; 2011

24. Case study: higher ed. Twitter: a community education. 2009. Online article available at http://twitter09.wordpress.com/the-book/ case-study-higher-ed/ (accessed August 2014)

25. Ovadia S. Internet connection: an early introduction to the Google+ social networking project. Beh Soc Sci Lib 2011; 30: 259-163.

26. Papacharissi $Z$ A. The virtual geographies of social networks: a comparative analysis of Facebook, Linkedln and ASmallWorld. New Media Soc 2009; 11: 199-220.

27. Wasserman T. Pinterest is now the number 3 social network in the U.S. Mashable, 2012. Online article available at $h t t p: / / m a s h a b l e . c o m / 2012 / 04 / 06 /$ pinterestnumber-3-social-network (accessed August 2014).

28. Duggan M, Smith A. Social media update 2013. Pew Research Centre, 2013. Online article available at http://www.pewinternet.org/files/old-media//Files/ Reports/2013/Social\%20Networking\%202013_PDF. pdf (accessed August 2014).

29. Mansfield S J, Morrison S G, Stephens H O et al. Social media and the medical profession. Med J Aust 2011; 194: 642-644.

30. Bosslet G T, Torke A M, Hickman S E, Terry C L, Helft $P R$. The patient-doctor relationship and online social networks: results of a national survey. J Gen Intern Med 2011; 26: 1168-1174.

31. Fox B, Faradrajan R. Use of Twitter to encourage interaction in a multi-campus pharmacy management course. Am J Pharm Educ 2011; 75: 88.

32. Arnett M, Loewen J, Romito L. Use of social media by dental educators. J Dent Educ 2013; 77: 1402-1412.

33. Social media: how doctors can contribute. Lancet 2012; 379: 1562

34. Giordano C, Giordano C. Health professions students' use of social media. J Allied Health 2011; 40: 78-81. 